School of Finance

University of St.Gallen

RESEARCH ON LAPSE IN LIFE INSURANCE - WHAT HAS BEEN DONE AND WHAT NeEDS TO BE DONE?

MARTIN ELING

MichAEL KOCHANSKI

Working PAPERS ON FinANCE No. 2012/24

INSTITUT FÜR VERSICHERUNGSWIRTSCHAFT (I.VW - HSG)

DECEMBER 2012 


\title{
Research on Lapse in Life Insurance-What Has Been Done and What Needs to Be Done?
}

Martin Eling, Michael Kochanski

\begin{abstract}
The intention of this paper is to review research on lapse in life insurance and to outline potential new areas of research in this field. We consider theoretical lapse rate models as well as empirical research on life insurance lapse and provide a classification of these two streams of research. More than 50 theoretical and empirical papers from this important field of research are reviewed. Challenges for lapse rate modeling, lapse risk mitigation techniques, and possible trends in future lapse behavior are discussed. The risks arising from lapse are of high economic importance. As such, lapsation is of interest not only to academics, but is also highly relevant for the industry, regulators, and policymakers.
\end{abstract}

JEL classification: G22; G28

Keywords: Lapse; Surrender; Lapse Modeling; Life Insurance 


\section{Introduction}

Today's insurance policies allow policyholders to choose among a large number of options that can significantly influence the extent of the insurer's liabilities (see Bauer et al., 2006; Gatzert, 2009; Kling et al., 2011). For example, policyholders can surrender their policy and receive a surrender value (the so-called surrender option) or they can opt to discontinue premium payments (the so-called paid-up option). Originally, the term "lapse" meant termination of an insurance policy and loss of coverage because the policyholder had failed to pay premiums (see Gatzert, 2009; Kuo et al., 2003). In the academic literature, however, lapse often denotes both termination of a policy accompanied by payout of a surrender value to the policyholder and termination without any payment (see, e.g., Renshaw and Haberman, 1986; Kuo et al., 2003). ${ }^{1}$ A broader definition of the term lapse also includes the paid-up option (see, e.g., Life Insurance and Market Research Association (LIMRA), 2005; Committee of European Insurance and Occupational Pensions Supervisors (CEIOPS), 2009). In the new European Union regulatory regime Solvency II, the lapse risk module covers "all legal or contractual policyholder options which can significantly change the value of the future cashflows. This includes options to fully or partly terminate, decrease, restrict or suspend the insurance cover as well as options which allow the full or partial establishment, renewal, increase, extension or resumption of insurance cover” (CEIOPS, 2010, p. 155).

The risks arising from lapse are of high economic importance for a variety of reasons. A massive lapse event can threaten the insurer's liquidity and force the selling of assets. Lapsation might also lead to a loss of potential future profits; specifically, early lapses could result in substantial losses if the insurer is not able to retrieve acquisition costs (Prestele, 2006, e.g., claims that only half the life insurance policies in Germany stay in force until the end of their

1 Lapse and surrender thus both refer to the termination of an insurance contract before maturity. While lapse often refers to the termination of policies without payout to policyholders, surrender typically indicates that a surrender value is paid out. In this work, lapse is used to refer to both the termination of an insurance contract with and without payout of a surrender value. This is in line with existing literature (e.g., Kuo et al. 2003; Eling and Kiesenbauer, 2011) and also consistent with standard measures of lapse which typically include both lapsed policies and surrendered ones. 
policy terms). Moreover, the option to lapse can enhance adverse selection, especially in cases when policyholders can lapse without incurring any substantial lapse fees. Lapses also diminish the effectiveness of risk pooling. Finally, high lapse rates can have a negative effect on the insurer's reputation, which might result in even more policyholders lapsing, as well as harm new business.

European Union regulators have identified lapse as one of the main risk drivers of life insurance companies. In fact, the recent Quantitative Impact Study (QIS) 5 of the new regulatory framework Solvency II showed that lapse risk is the most important risk among life underwriting risks (see EIOPA, 2011). Moreover, recent history shows that lapses can be problematic for life insurers facing solvency issues. According to the Comité Européen des Assurances (CEA, 2009), companies such as Equitable Life, Standard Life, and Mannheimer Holding experienced significantly increasing lapse rates in the course of their turmoil. As an analogue to bank run, Harrington (1992) uses the term "policyholder run” to describe the problems several insurers faced in the late 1980's. Thus, research on lapse rates is crucial to a proper calibration of regulatory standard models (see, e.g., Watson Wyatt, 2004; CEIOPS, 2009) and internal risk models, among other reasons.

The aim of this paper is to review what research has already been done on life insurance lapse and to foster future research by outlining what needs to be done in this important field. The core of this paper is a structured review of 44 theoretical and 12 empirical papers on life insurance lapse. Only seven of the 56 papers are published before the year 2000, which emphasizes the increasing importance and topicality of this field of research in actuarial literature. ${ }^{2}$ Lapsation is of interest not only to academics, but is of high importance for the industry, regulators, and policymakers, especially in regard to designing an appropriate regulatory environment. Moreover, lapsation impacts many actuarial tasks, such as product design, pricing, hedging, and risk management.

2 The intention of our paper is not to provide details regarding the mathematical work, but to focus on the insurance economic content of the models, both from a theoretical and from an empirical perspective. 
The remainder of the paper is organized as follows. Section 2 reviews the existing lapse research. We first consider theoretical lapse rate models, reviewing terminology and providing a classification by product type and modeling approach. Then we review empirical research on life insurance lapse, again providing a classification including product type and modeling approach. Here we also review potential data sources for lapse research that shall help researchers to get an overview of appropriate data. In Section 3 we outline potential avenues for future research. We discuss challenges for future lapse rate models, lapse risk mitigation techniques, and possible trends in future lapse behavior. Of course, this discussion is subjective in nature, but our hope is that it might serve as a helpful outline for academics and practitioners interested in lapse research. We conclude in Section 4.

\section{Theoretical Models and Empirical Evidence}

\subsection{Lapse Models}

In this section, we discuss lapse rate models presented in academic literature. We first analyze the current academic terminology and use this to develop a general framework for lapse rate modeling. The general framework should not be understood as a quantitative model; it rather should serve as a qualitative framework summarizing the most important aspects in modeling lapse rates. Based upon these thoughts, we then discuss different lapse rate models.

\subsubsection{Framework for a General Lapse Rate Model}

To date, the academic literature is not consistent in terminology regarding lapse. Consiglio and De Giovanni (2010) differentiate between "lapse behavior [due] to economic and/or social factors, such as the unemployment rate, interest rate, age, education, etc." and "an internal decision process, where the investor rationally exercises his right to surrender the policy.” De Giovanni (2010) specifies optimal lapse behavior and not optimal behavior, defining the first as the situation "where policyholders rationally choose whether to exercise the option or not” (again as an internal decision process). Not optimal behavior is specified as "irrational surrenders.” The terms exogenous and endogenous are used by Bacinello (2005), among oth- 
ers. A more detailed classification is made by Li and Szimayer (2010), who distinguish "exogenous reasons," "the surrender option as an American-style contingent claim to be exercised rationally," “suboptimal surrender” with a "decision parameter,” and "portfolio level surrender" characterized by an "increasing function of the ratio of the surrender value and the value when holding the contract until maturity.”

As starting point for the development of a general lapse rate model, we assign the above terminology to deterministic and dynamic lapse. Deterministic lapsation is not scenario specific and thus can be considered within offline calculations. For performance reasons, internal risk models of insurance companies should be designed to perform as many calculations as possible outside of the scenario-specific online calculations in order to avoid redundancy. Lapse drivers that are scenario specific are classified as dynamic. An overview of the terminology in the context of a general lapse rate model, along with some examples, is presented in Figure 1. The left part of Figure 1 shows the variety of information that can be used as lapse drivers. In a lapse rate model these can then either be used scenario-independent which results in a deterministic lapse rate model or these can be incorporated in scenarios which then results in a dynamic lapse rate model. Note that the classification strongly depends on the model, for example of the financial market model.

Dynamic lapsation is a result of an internal decision process, therefore we classify endogenous lapse according to Bacinello (2005) as dynamic. Exogenous lapsation that depends on external factors is classified as deterministic. Usually, social, individual and economic factors are modeled deterministic, but some of these factors (e.g., health status, GDP, unemployment rate) are also suitable for stochastic modeling and therefore can also be used for modeling dynamic lapsation. Social, individual, and economic factors might lead to irrational lapsa- 
tion, $^{3}$ whereas rational lapsation depends on factors such as market rates and in-themoneyness or value of guarantees. Full rationality leads to optimal behavior and is usually modeled as dynamic lapse. ${ }^{4}$

\begin{tabular}{|c|c|c|c|}
\hline \multicolumn{2}{|c|}{ Information used in lapse models } & \multirow{3}{*}{$\begin{array}{l}\text { lapse drivers are scenario- } \\
\text { independent or have negligible } \\
\text { effect on lapse behavior }\end{array}$} & \multirow{2}{*}{$\begin{array}{l}\text { Model Categories } \\
\begin{array}{c}\text { deterministic } \\
\text { lapse rate models } \\
\text { (lapse rate tables / lapse } \\
\text { base rates) }\end{array}\end{array}$} \\
\hline $\begin{array}{l}\text { (Historical) policy portfolio data } \\
\text { - age } \\
\text { - gender } \\
\text { : product/policy type } \\
\text { - } \text { sistribution channel } \\
\text { : health status } \\
\text { - historical lapse rates }\end{array}$ & $\begin{array}{l}\text { Expert knowledge } \\
\text { Assumptions on future policyholder } \\
\text { behavior based on behavioral science } \\
\text { and experience } \\
\text { - regulator } \\
\text { - reinsurer } \\
\text { - consultant } \\
\text { - insurance association } \\
\text { academic research }\end{array}$ & & \\
\hline $\begin{array}{l}\text { Publicly available information } \\
\text { - GDP growth } \\
\text { - unemployment rates }\end{array}$ & $\begin{array}{l}\text { Scenario generator } \\
\text { - financial market scenarios } \\
\text { - non-financial scenarios (e.g., health } \\
\text { status, policyholder interaction) }\end{array}$ & & $\begin{array}{l}\text { general lapse rate models } \\
\text { incorporating deterministic } \\
\text { and dynamic lapse } \\
\text { - dynamic lapsation allowing } \\
\text { for suboptimal behavior }\end{array}$ \\
\hline \multicolumn{2}{|c|}{$\begin{array}{l}\text { Portfolio projection } \\
\text { Projections of policy value, surrender value, continuation value... } \\
\text { - in-the-moneyness or value of options and guarantees } \\
\text { profit participation } \\
\text { Assumptions on risk-preferences of policyholders and grade of rationality of the } \\
\text { policyholders' decision-making }\end{array}$} & $\begin{array}{l}\text { lapse drivers are scenario- } \\
\text { specific and have significant } \\
\text { effect on lapse behavior }\end{array}$ & $\begin{array}{l}\text { dynamic } \\
\text { lapse rate models } \\
\text { - optimal dynamic lapsation } \\
\text { assuming rational and risk- } \\
\text { neutral investors } \\
\text { - optimal dynamic lapsation } \\
\text { assuming rational and risk- } \\
\text { averse investors }\end{array}$ \\
\hline
\end{tabular}

Figure 1: Framework of a lapse rate model

\subsubsection{Lapse Rate Models}

The academic literature on lapse models has expanded the traditionally consideration of deterministic lapse rate tables to a dynamic modeling of lapse rates. In the following, we distinguish the dynamic lapse rate models introduced in literature by their assumptions about policyholder rationality and by the considered product type. With respect to rationality, we distinguish among pure dynamic lapse rate models that allow for optimal dynamic lapsation assuming rational and risk-neutral investors (Table 1) and optimal dynamic lapsation assuming rational and risk-averse investors (Table 2). General Lapse rate models that incorporate

3 Note that policyholders who lapse for these reasons usually are behaving very rationally from their point of view so that irrational lapsation only refers to the modeling standpoint. This illustrates that-like many modeling approaches-lapse rate models reflect only a part of the true decision-making process.

4 Note that in simple internal models market rates are often deterministic which then leads to rational or optimal lapse modeled as deterministic lapse. 
dynamic and deterministic lapse offer the possibility to model suboptimal lapsation (Table 3). Regarding the product type, life insurance products can be classified into three broad categories: traditional products, unit-linked products, and variable annuities.

Most academic literature treats policyholders as financially rational and risk neutral. In a given financial market model, policyholders are assumed to act optimally in terms of maximizing the terminal value of their investment. With these assumptions, homogeneous insurance portfolios will either lapse entirely or not at all. The surrender option can be interpreted as an American option; its value can be determined by solving an optimal stopping problem. Although this framework obviously does not reflect reality, it is useful. Assuming that policyholders usually act less than optimally, this model can be viewed as a worst-case model of policyholder behavior (from an insurer's point of view). Table 1 summarizes work that falls into this category depending on product type and presents the used valuation methods.

\begin{tabular}{lll}
\hline Product type & Papers & Valuation method \\
\hline Traditional products & Grosen and Jorgensen (2000) & Cox-Ross-Rubinstein \\
(with-profit or profit- & Jensen et al. (2001) & Partial Differential Equation (PDE) \\
participating life in- & Bacinello (2003a) & Cox-Ross-Rubinstein \\
surance, e.g., en- & Bacinello (2003b) & Cox-Ross-Rubinstein \\
dowments, annuities, & Tanskanen and Lukkarinen (2003) & PDE \\
etc.) & Andreatta and Corradin (2003) & Longstaff and Schwartz \\
& Bauer et al. (2006) & PDE \\
& Nordahl (2008) & Longstaff and Schwartz \\
Unit-linked products & Grosen and Jorgensen (1997) & PDE \\
(with and w/o guaran- & Steffensen (2002) & PDE \\
tees, e.g., equity- & Vannucci (2003) & Cox-Ross-Rubinstein \\
indexed annuities) & Bacinello (2005) & Cox-Ross-Rubinstein \\
& Shen and Xu (2005) & PDE \\
& Consiglio and De Giovanni (2010) & Super-replication \\
Variable annuities & Milevsky and Salisbury (2001) & PDE \\
(GMxB's) & Milevsky and Salisbury (2006) & PDE \\
& Chen et al. (2008) & PDE \\
& Kling et al. (2011) & Longstaff and Schwartz \\
\hline
\end{tabular}

Table 1: Optimal dynamic lapsation assuming rational and risk-neutral policyholders

A rational and risk-neutral policyholder immediately surrenders an insurance policy when the surrender value exceeds the continuation value. The surrender value is usually given or can easily be calculated at any point of time within the model while the calculation of the continuation value requires some effort. Since the continuation value depends on future states of the 
financial market model, the valuation of the surrender option requires a backward approach. The algorithm can be demonstrated with a simple binomial tree (see Figure 2), similarly used by the Cox-Ross-Rubinstein valuation method. Let $F_{t}, t \in(0, \ldots, T)$, denote the policyholder's account value. $C_{T}=\max \left(F_{T}, G\right)$ denotes the value of the policy at maturity, where $G$ is an endpoint guarantee. $R_{t}=F_{t}-s, t \in(0, \ldots, T-1)$ is the surrender value, where $s$ is a surrender fee. Starting with an initial account value at $t=0$ we can derive all values for $F_{t}$, the maturity value and the surrender values. Now, beginning at $t=T-1$ and going backwards, we can derive the continuation values (assuming no surrender at $t$ ) $W_{t}=\omega^{u} V_{t+1}^{u}+$ $\omega^{d} V_{t+1}^{d}, t \in(0, \ldots, T-1)^{5}$, and the total value of the policy $V_{t}=\max \left(W_{t}, R_{t}\right), t \in$ $(0, \ldots, T-1)$, and $V_{T}=C_{T}$.
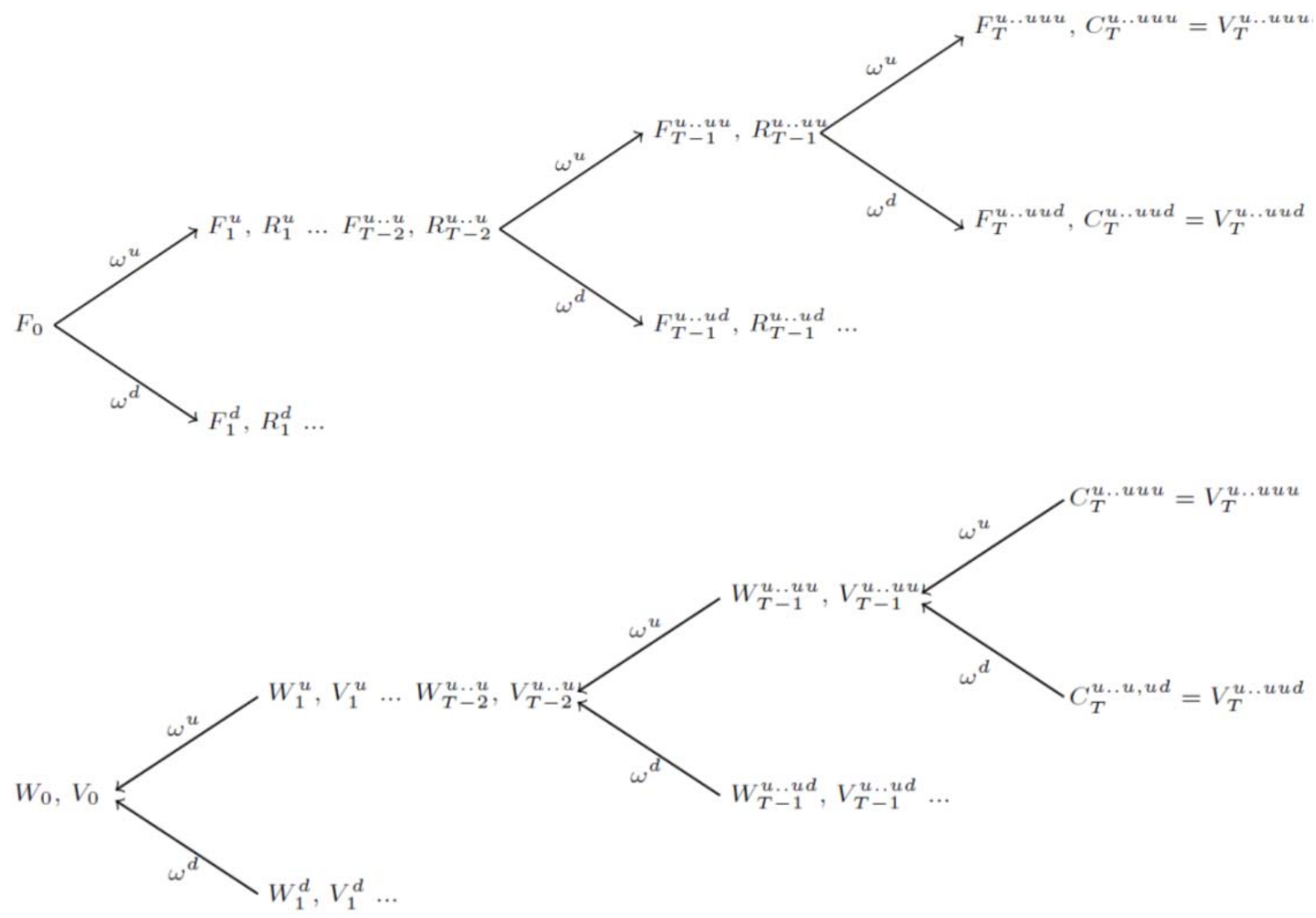

Figure 2: Valuation of the surrender option within a binomial model

${ }^{5} \omega_{1}$ and $\omega_{2}$ denote the probabilities of the states with $\omega_{1}+\omega_{2}=1$. 
The value of the surrender option is then defined as the difference between the total values of the policy at $t=0$ calculated with and without the surrender option. Unfortunately, sophisticated financial market models, a complex composition of the insurer's asset portfolio and the existence of other financial guarantees make it impossible to value surrender options using the Cox-Ross-Rubinstein (CRR) model or even to derive closed-form solutions by solving partial differential equations (PDE). Therefore, the models of the papers stated in Table 1 using the CRR or the closed-form PDE valuation method are heavily simplified and of limited practical use. For example, Bacinello (2005) uses a binomial model with a stochastic fund value, a constant risk free rate, a deterministic decrement model and simple (linear or maximum) functions for the benefit at maturity and death as well as the surrender value.

Expanding the valuation approach of the CRR by not posing restrictions to the model in use, the Longstaff and Schwartz method is commonly used by today's practitioners, not only for the valuation of surrender options but for many actuarial problems involving nested simulations. The restriction here is, as with all simulation methods, the limit on computational capacities.

The framework presented in Table 1 can be generalized by removing the assumption of riskneutral policyholders and the maximization of the terminal value of their investment. The literature listed in Table 2 assumes that policyholders act to maximize their expected utility. This framework allows for risk-averse policyholders engaging in a more complex decision process. Justified by bequest motives, the decision process can also account for death benefits. All papers presented in Table 2 use utility functions from the class of constant relative risk aversion.

\begin{tabular}{llll}
\hline Product type & Papers & Class of utility function & Utility parameters \\
\hline Traditional products & Kraft and Steffensen (2008) & Constant Relative Risk & bequest, consumption \\
& & Aversion (CRRA) & and annuity benefits \\
\multirow{2}{*}{ Unit-linked products } & Moore and Young (2005) & CRRA & bequest \\
& Cheung and Yang (2005) & CRRA & surrender value \\
& Moore (2009) & CRRA & bequest \\
Variable annuities & Moenig and Bauer (2011) & CRRA & consumption, bequest \\
\hline
\end{tabular}

Table 2: Optimal dynamic lapsation assuming rational and risk-averse investors 
For example, Cheung and Yang (2005) obtain an optimal surrender policy for cliquet-style equity-indexed annuities (EIAs). They use a discrete-time Markovian regime switching model and a CRRA utility function. The value process of the EIA can be denoted by $W_{t}=$ $W_{0} \prod_{k=0}^{t-1} f\left(R_{k}^{\omega_{k}}\right)$ with the return of the reference index $R_{k}^{\omega_{k}}$ in $[k, k+1]$ under the regime $\omega_{k}$. The policyholder maximizes his expected discounted utility over a stopping time $\tau$. Given that no surrender charges apply, the problem can be described by $\max _{\tau \in \mathrm{T}_{\mathbf{o}}} \mathrm{E}\left[\frac{U\left(W_{\tau}\right)}{(1+r)^{\tau}}\right]$ with an increasing and concave utility function $U(W)=\frac{W^{\gamma}}{\gamma}, 0<\gamma<1$.

The assumption of optimal behavior can be relaxed by introducing a threshold, i.e. a decision parameter or transaction costs that allows for lapsation only when it is significantly beneficial to lapse the policy. This approach, as done by Ho et al. (2005), Chen et al. (2008) and Bernard and Lemieux (2008), leads to a special case of suboptimal behavior but is not capable of allowing for deterministic lapse. Dynamic lapse rate models can, however, also include deterministic elements which then incorporate suboptimal behavior (see Table 3). In Figure 1, we categorize these models as general lapse rate models that include both dynamic and deterministic elements.

\begin{tabular}{lll}
\hline Product type & Papers & Dynamic lapse driver \\
\hline Traditional products & Smink (1991) & $\Delta r$ \\
& Albizzati and Geman (1994) & $\Delta r$ \\
& Zenios (1999) & $\Delta r$ \\
& Tsai et al. (2009) & $\Delta r$ \\
& De Giovanni (2010) & $\Delta r$ \\
& Morgan (2010) & unrealized losses \\
& Loisel and Milhaud (2011) & $\Delta r$ \\
Unit-linked products & Le Courtois and Nakagawa (2011) & r, S \\
& Kolkiewicz and Tan (2006) & Volatility \\
& Anzilli and De Cesare (2007) & advertising \\
Variable annuities & Kochanski (2010) & rate of return \\
& Li and Szimayer (2010) & MSO \\
& American Academy of Actuaries (2005) & MSO \\
All product categories: & Ledlie et al. (2008) & MSO \\
\hline
\end{tabular}

Notes: $\Delta r=$ spread of the market rate to the policy rate; $\mathrm{MSO}=$ moneyness of the surrender option ${ }^{6}$; OV = surrender option value.

Table 3: Dynamic lapsation allowing suboptimal behavior

6 The moneyness of the surrender option expresses the relationship between the surrender value and the continuation value or account value of the policy. 
Two popular modeling techniques have emerged for constructing combined lapse rates. The lapse intensity can be decomposed into a constant, representing the deterministic lapses, and a dynamic variable, representing dynamic lapse. The combined lapse rate is then calculated using the multiple decrement model. This technique is used by Kolkiewicz and Tan (2006), Tsai et al. (2009), De Giovanni (2010), Li and Szimayer (2010), and Le Courtois and Nakagawa (2011). In accordance with Kolkiewicz and Tan (2006), we define the baseline hazard rate function $\mu_{\text {det }}(t)$ and the stochastic hazard rate function $\mu\left(t, \theta_{t, 1}, \ldots, \theta_{t, n}\right)$ with $\theta_{i}$ denoting the lapse drivers. Then the lapse rate $l_{t-1, t}$ on the interval $[t-1, t]$ can be obtained by:

$$
l_{t-1, t}=1-\exp \left(-\int_{t-1}^{t} \mu_{d e t}(s)+\mu\left(s, \theta_{s, 1}, \ldots, \theta_{s, n}\right) d s\right) .
$$

The other technique uses deterministic lapse rates as base rates, which can be adjusted by dynamic factors, the so-called dynamic lapse multipliers. This technique is used by the American Academy of Actuaries (2005), Morgan and Kent (2008), Ledlie et al. (2008), Kochanski (2010), Morgan (2010), and Kling et al. (2011). Let $l_{t-1, t}^{\text {det }}$ denote the lapse base rate and $d m_{i}\left(t, \theta_{t, i}\right)$ denote the dynamic lapse multipliers with $\operatorname{dlm}_{i}\left(t, \theta_{i}\right)>0$ and the lapse drivers $\theta_{t, i}$. Then the lapse rate $l_{t-1, t}$ on the interval $[t-1, t]$ can be obtained by:

$$
l_{t-1, t}=\max \left(l_{t-1, t}^{\text {det }} \cdot \prod_{i=1}^{n} d l m_{i}\left(t, \theta_{t, i}\right), 1\right) .
$$

It is also possible to combine these two both modeling techniques as well as to expand the model in order to achieve maximal flexibility with respect to type and number of lapse drivers. Most papers use the spread of the market rate to the policy rate or the moneyness of the surrender option (i.e. the proportion of the surrender value to the continuation value of the insurance policy) as a dynamic lapse driver. Both academics and practitioners consider these as the two main drivers of dynamic lapses. Since lapse rates can also be driven by multiple factors, some other interesting drivers have been implemented in dynamic lapse rate models. Le Courtois and Nakagawa (2011) introduce a stochastic lapse rate correlated with stochastic interest rates and other risky assets. In Kolkiewicz and Tan (2006), the lapse rate is driven by 
stochastic volatility and Kochanski (2010) uses the return of the policies' assets as a lapse driver. Anzilli and De Cesare (2007) presents dynamic lapses driven by mass media advertising, while Morgan (2010) uses the proportion of unrealized losses to the policies’ assets.

\subsection{Empirical Evidence}

We now turn to empirical studies of life insurance lapse. The literature presented in Table 4 can be subdivided into two parts depending on the explanatory variables considered. The first set of literature, presented in Panel A of Table 4, focuses on environmental variables (i.e., macro-economic indicators or company characteristics). The second set of literature, presented in Panel B of Table 4, focuses on product and policyholder features. More research has been published on the first set (environmental variables) since publicly available data can be used. There is less work focusing on policyholder and product characteristics since individual data on policies are needed which is typically confidential. Moreover, in some cases the data might not be available at the company level because of system changes, migrations, or even the non-existence of an appropriate data warehouse. For both streams of literature we present the countries covered, the types of policies, the time period, variables, and main results (the structure of Panel B of Table 4 is oriented at Eling and Kiesenbauer, 2011, who also provide an empirical analysis of the German market and discuss more details on the product and policyholder characteristics).

\subsubsection{Data Sources for Lapse Analysis}

An important basis for research on life insurance lapse is the profound knowledge on what type of data is available from which sources. For this reason we first describe the various data sources that have been considered in literature which might be helpful for researchers to identify the data available. We thereby focus on the information on lapse (most studies consider additional data on unemployment rates or interest rates which are then taken from the respective countries statistical yearbooks (e.g. the Bank of England Quarterly Bulletin) or supranational institutions (such as, e.g., the International Monetary Fund)). 


\section{Panel A: Focus on environmental variables}

\begin{tabular}{|c|c|c|c|c|c|c|c|}
\hline Authors & Dar and Dodds (1989) & Outreville (1990) & Kuo et al. (2003) & Kim (2005a) & $\operatorname{Kim}(2005 b)$ & Cox and Lin (2006) & Kiesenbauer (2011) \\
\hline Country & UK & US, Canada & US & South Korea & US & & Germany \\
\hline $\begin{array}{l}\text { Lapse Data } \\
\text { Provider }\end{array}$ & $\begin{array}{l}\text { Industrial Life Offices' } \\
\text { Association (ILOA) }\end{array}$ & $\begin{array}{l}\text { American Council of } \\
\text { Life Insurance (ACLI); } \\
\text { Life Insurance and } \\
\text { Market Research As- } \\
\text { sociation (LIMRA) }\end{array}$ & $\begin{array}{l}\text { American Council } \\
\text { of Life Insurance } \\
\text { (ACLI) }\end{array}$ & $\begin{array}{l}\text { One Korean compa- } \\
\text { ny }\end{array}$ & $\begin{array}{l}\text { Society of Actuaries' Risk } \\
\text { Management Task Force } \\
\text { (data on one US compa- } \\
\text { ny) }\end{array}$ & $\begin{array}{l}\text { Society of Actuaries' } \\
\text { Risk Management Task } \\
\text { Force (data on one US } \\
\text { company) }\end{array}$ & $\begin{array}{l}\text { German regulator BAFin } \\
\text { and self-collected data }\end{array}$ \\
\hline Type of Policy & Endowment policies & $\begin{array}{l}\text { Whole-life and ordinary } \\
\text { life insurance }\end{array}$ & $\begin{array}{l}\text { All ordinary life } \\
\text { insurance con- } \\
\text { tracts }^{*}\end{array}$ & $\begin{array}{l}\text { Endowment, annuity, } \\
\text { protection plan, edu- } \\
\text { cation }\end{array}$ & $\begin{array}{l}\text { Single premium deferred } \\
\text { annuities }\end{array}$ & $\begin{array}{l}\text { Single premium } \\
\text { deferred annuities }\end{array}$ & $\begin{array}{l}\text { Endowment, annuities } \\
\text { including disability and } \\
\text { long-term care, term life, } \\
\text { group business, other }\end{array}$ \\
\hline Time Period & $1952-1985$ & $\begin{array}{l}\text { 1955-1979 (annually), } \\
\text { 1966-1979 (semiannu- } \\
\text { aly) }\end{array}$ & $1951-1998$ & $1997-2000$ & $1993-2003$ & $1993-2003$ & $1997-2009$ \\
\hline Methods & $\begin{array}{l}\text { Standard time series } \\
\text { regressions }\end{array}$ & $\begin{array}{l}\text { Standard time series } \\
\text { regressions }\end{array}$ & $\begin{array}{l}\text { Cointegration } \\
\text { techniques }\end{array}$ & $\begin{array}{l}\text { Logit and comple- } \\
\text { mentary log-log mod- } \\
\text { el }\end{array}$ & Logit & Tobit & Logistic regression \\
\hline \multirow[t]{2}{*}{$\begin{array}{l}\text { Variables for } \\
\text { EFH and IRH }\end{array}$} & $\begin{array}{l}\text { EFH: growth in the } \\
\text { level of unemployment } \\
\text { and the level of actual } \\
\text { unemployment relative } \\
\text { to time trend }\end{array}$ & $\begin{array}{l}\text { EFH: yearly unem- } \\
\text { ployment rate }\end{array}$ & $\begin{array}{l}\text { EFH: yearly un- } \\
\text { employment rate }\end{array}$ & $\begin{array}{l}\text { EFH: Unemployment } \\
\text { rate }\end{array}$ & $\begin{array}{l}\text { EFH: Monthly annualized } \\
\text { US unemployment rate }\end{array}$ & $\begin{array}{l}\text { EFH: Monthly annual- } \\
\text { ized US unemployment } \\
\text { rate }\end{array}$ & EFH: Unemployment rate \\
\hline & $\begin{array}{l}\text { IRH: internal and ex- } \\
\text { ternal rate of return }\end{array}$ & $\begin{array}{l}\text { IRH: real rate of return } \\
\text { on alternative assets }\end{array}$ & $\begin{array}{l}\text { IRH: market inter- } \\
\text { est rates }\end{array}$ & $\begin{array}{l}\text { IRH: reference mar- } \\
\text { ket rate - crediting } \\
\text { rate -surrender } \\
\text { charges }\end{array}$ & $\begin{array}{l}\text { IRH: Annualized five-- } \\
\text { year Treasury bond rate } \\
\text { minus the policy credited } \\
\text { rate }\end{array}$ & $\begin{array}{l}\text { IRH: Annualized five- } \\
\text { year Treasury bond rate } \\
\text { minus the policy credited } \\
\text { rate }\end{array}$ & $\begin{array}{l}\text { IRH: Bond Performance, } \\
\text { Stock Performance }\end{array}$ \\
\hline $\begin{array}{l}\text { Other } \\
\text { variables }\end{array}$ & / & $\begin{array}{l}\text { Real transitory income } \\
\text { per capita, price of } \\
\text { insurance, anticipated } \\
\text { inflation rate. }\end{array}$ & I & $\begin{array}{l}\text { Policy age, GDP } \\
\text { growth, surrender } \\
\text { charge }\end{array}$ & $\begin{array}{l}\text { Policy age, GDP growth, } \\
\text { surrender charge }\end{array}$ & $\begin{array}{l}\text { Policy age, GDP growth, } \\
\text { surrender charge }\end{array}$ & $\begin{array}{l}\text { Buyer confidence, GDP, } \\
\text { company age, distribu- } \\
\text { tion, legal form, company } \\
\text { size, participation rate }\end{array}$ \\
\hline Main Results & $\mathrm{EFH}+; \mathrm{IRH}-$ & $\mathrm{EFH}+$ & $\mathrm{EFH}-, \mathrm{IRH}+$ & $\begin{array}{l}\text { Lapse depends on } \\
\text { additional exogenous } \\
\text { factors beyond inter- } \\
\text { est rates and unem- } \\
\text { ployment rates }\end{array}$ & $\begin{array}{l}\text { Logit Model closely fit the } \\
\text { experience of the data } \\
\text { even under extreme } \\
\text { financial conditions }\end{array}$ & $\begin{array}{l}\text { Tobit model is better } \\
\text { than logit model; pois- } \\
\text { son and the negative } \\
\text { binomial regression } \\
\text { model are more appro- } \\
\text { priate to model lapse }\end{array}$ & $\begin{array}{l}\text { Factors beyond interest } \\
\text { rates and unemployment } \\
\text { influence lapse behavior, } \\
\text { including company char- } \\
\text { acteristics }\end{array}$ \\
\hline
\end{tabular}

that includes limited payment, decreasing, level and other term, term additions), and endowment insurance.

Table 4: Empirical literature on life insurance lapse 
Panel B: Focus on product and policyholder characteristics

\begin{tabular}{|c|c|c|c|c|c|}
\hline Authors & $\begin{array}{l}\text { Renshaw and Haberman } \\
(1986)\end{array}$ & Kagraoka (2005) & Cerchiara et al. (2009) & Milhaud et al. (2010) & Eling and Kiesenbauer (2011) \\
\hline Country & Scotland & Japan & Italy & Spain & Germany \\
\hline Data Provider & Pool of 7 companies & 1 company & 1 company & 1 company & 1 company \\
\hline Type of Policy & $\begin{array}{l}\text { Endowment } \\
\text { Whole-life } \\
\text { Temporary insurance }\end{array}$ & Annuity-type personal accident & Saving & Endowment & $\begin{array}{l}\text { Endowment } \\
\text { Annuity } \\
\text { Term life }\end{array}$ \\
\hline Time Period & 1976 & 1993-2001 & 1991-2007 & 1999-2007 & $2000-2010$ \\
\hline Methods & $\begin{array}{l}\text { Logistic regression model } \\
\text { Binomial model }\end{array}$ & $\begin{array}{l}\text { Poisson model } \\
\text { Negative binomial model }\end{array}$ & Poisson model & $\begin{array}{l}\text { Logistic regression model } \\
\text { Classification and regression tree } \\
\text { model }\end{array}$ & $\begin{array}{l}\text { Poisson model } \\
\text { Binomial model } \\
\text { Negative binomial model }\end{array}$ \\
\hline Variables & $\begin{array}{l}\text { Policyholder age and sex } \\
\text { Contract age } \\
\text { Product type } \\
\text { Company }\end{array}$ & $\begin{array}{l}\text { Policyholder age and sex } \\
\text { Seasonality } \\
\text { Unemployment rate } \\
\text { Heterogeneity }\end{array}$ & $\begin{array}{l}\text { Policyholder age } \\
\text { Contract age } \\
\text { Product type } \\
\text { Calendar year }\end{array}$ & $\begin{array}{l}\text { Policyholder age } \\
\text { Contract age } \\
\text { Product type } \\
\text { Sum insured } \\
\text { Risk premium } \\
\text { Saving premium }\end{array}$ & $\begin{array}{l}\text { Policyholder age and sex } \\
\text { Contract age } \\
\text { Product type }\end{array}$ \\
\hline Main Results & $\begin{array}{l}\text { four factors identified as im- } \\
\text { portant (age at entry, duration } \\
\text { of policy, office, type of policy); } \\
\text { additionally, significant interac- } \\
\text { tion between policy type and } \\
\text { duration }\end{array}$ & $\begin{array}{l}\text { surrender of the insurance con- } \\
\text { tracts is explained by change of } \\
\text { unemployment rates and time } \\
\text { elapsed from contract date. }\end{array}$ & $\begin{array}{l}\text { Shows the importance of } \\
\text { policy duration, but also } \\
\text { show the sensitivity of } \\
\text { lapse rates to calendar year } \\
\text { of exposure, to product } \\
\text { class and policyholder age }\end{array}$ & $\begin{array}{l}\text { Find that duration and profit benefit } \\
\text { option are essential }\end{array}$ & $\begin{array}{l}\text { Product characteristics such as } \\
\text { product type or contract age and } \\
\text { policyholder characteristics such } \\
\text { as age or gender are important } \\
\text { lapse drivers }\end{array}$ \\
\hline
\end{tabular}

Table 4: Empirical literature on life insurance lapse (continued) 
Regarding the United Kingdom, Dar and Dodds (1989) consider surrender data from the Industrial Life Offices' Association (ILOA). This association ceased to exist in 1985 when its functions were transferred to the Association of British Insurers. More recent information is also collected by the U.K. Financial Services Authority (FSA), e.g., in their 2010 survey of the persistency of life and pensions policies (see FSA, 2010). In the 1990's data was also collected by the Personal Investment Authority (PIA), but their responsibilities were transferred to the FSA.

For the United States, lapse rates are reported by the American Council of Life Insurance (ACLI) in its annual publication "Life Insurance Fact Book.” The data are derived from annual statements filed with the US national regulator, the NAIC (National Association of Insurance Commissioners), ACLI's surveys, and external sources such as government agencies and trade associations. The data has been used by Outreville (1990) and Kuo et al. (2003). Moreover, since 1961 the Life Insurance and Market Research Association (LIMRA) compiled volume data of ordinary life insurance that lapses within 13 months of issue or conversion (early lapse) and publishes these semi-annually in the as the United States and Canadian "I3Month Ordinary Lapse Survey.”(see Outreville, 1989). Another source of data used in literature comes from the Society of Actuaries’ Risk Management Task Force (see Kuo et al., 2005b; Cox and Lin, 2006). In 2005 the Society of Actuaries also sponsored a joint study with LIMRA which considers pooled data from 22 participating companies (see Purushotham, 2005).

As mentioned, LIMRA also collects semi-annual lapse information for Canada. Besides the LIMRA data, annual rates on all whole-life policies have been computed with the data of the “Annual Report of the Superintendent of Insurance” in Canada (see Outreville, 1990). In Germany, Kiesenbauer (2011) considered lapse data which is collected by the German regulator BaFin. 
All empirical studies considering individual policyholder data (Panel B in Table 4) use confident information from one company. An exception is the early work by Renshaw and Habermann (1986) which consider pooled data from seven Scottish life insurance companies which has been provided by the Scottish Faculty of Actuaries.

\subsubsection{Evidence for Environmental Variables}

The research on environmental causes of life insurance lapse focuses on two prominent hypotheses, the "interest rate hypothesis" and the "emergency fund hypothesis." The interest rate hypothesis states that lapse rates are negatively related to internal rates of return (such as surplus participation), and positively related to external rates of return (such as market interest rates or stock returns; see Dar and Dodds (1989) or Kuo et al. (2003) for more details). The emergency fund hypothesis claims that personal financial distress forces policyholders to lapse their contracts in order to access the surrender value (see, e.g., Outreville, 1990). These two hypotheses are studied empirically in Dar and Dodds (1989), Outreville (1990), and Kuo et al. (2003). The empirical findings are not consistent, which may be due to differences in the markets, product types, methods, time periods, and variable specifications employed.

- Dar and Dodds (1989) test both the interest rate hypothesis and the emergency fund hypothesis considering lapse data for endowment policies in the United Kingdom. They find evidence in favor of the emergency fund hypothesis, but no significant relationship between surrenders and rate of return.

- Outreville (1990) studies the emergency fund hypothesis with lapse data of whole-life insurance in the United States and Canada. The results provide consistent evidence for the emergency fund hypothesis.

- Kuo et al. (2003) investigate both hypotheses using U.S. data and cointegration techniques in order to address long-term lapse dynamics. They find that the interest rate effect is economically more significant than the unemployment rate in explaining lapse rates. 
Overall, the interest rate hypothesis finds more support than the emergency fund hypothesis. Another aspect which might become more and more relevant in the context of the interest rate hypothesis is the secondary market for life insurance. In this case, life settlement providers or other market participants purchase life insurance policies. With the increasing growth in this market it might substantially affect future lapse rates. Other relevant aspects that might make the interest rate hypothesis even more relevant in the future are the trends towards lower surrender fees, higher transparency and better information of the policyholders.

As shown in Panel A of Table 4, three studies focus on interest rates and/or unemployment as indicator for adverse economic conditions. Kim (2005a, 2005b), Cox and Lin (2006), and Kiesenbauer (2011) go further by considering a broader set of economic variables and by also including selected company characteristics in the analysis. All these papers use the same broad class of generalized linear models.

Kim (2005a) models aggregate lapse rates of a South Korean insurer for four product categories (endowment, annuity, protection plan, and education). The contract age since policy inception is considered as product characteristic. Their results show that policyholder lapse behavior depends on additional exogenous factors beyond interest rates and unemployment rates. Kim (2005b) and Cox and Lin (2006) use a comparable set of explanatory variables and analyze single premium deferred annuity business in the United States. They arrive at similar conclusions as Kim (2005a). Moreover, Cox and Lin (2006) indicate that the Poisson and the negative binomial regression models are more appropriate for modeling lapse behavior, but that these models require individual (i.e., single contract) rather than aggregate lapse rate data. Finally, Kiesenbauer (2011) analyzes lapse in the German life insurance market using the same modeling approach as Kim (2005a). He employs market data to study lapse behavior with respect to economic indicators and additional company characteristics such as company 
age, company size, or legal form. The results support the conclusion that factors beyond interest rates and unemployment influence lapse behavior, including company characteristics.

\subsubsection{Evidence for Policyholder and Product Characteristics}

The literature analyzing individual contract data with respect to product and policyholder characteristics is very limited, possibly because this type of data is typically treated as confidential. Only aggregated lapse rate information is publicly available in most life insurance markets. An analysis of product and policyholder characteristics, however, requires more detailed data, which can only be provided by life insurers.

As shown in Panel B of Table 4, Renshaw and Haberman (1986) is the only paper that considers data from more than one company. All other papers use data from only one life insurer and consider only one product category (with the exception of Eling and Kiesenbauer, 2011, who consider multiple product categories). Again, all studies use generalized linear models to identify relevant contract features and policyholder characteristics.

The findings from the empirical studies regarding product and policyholder characteristics are not directly comparable since they use different data samples and explanatory variables. However, all studies identify a number of significant explanatory variables. Moreover, Renshaw and Haberman (1986) find an additional significant interaction between policy type and duration of policy. This finding can be interpreted to mean that lapse rates do not depend on one factor only, but on a combination of factors. All characteristics considered in Kagraoka (2005) are identified as significant, including the change in unemployment rate as an economic indicator. The latter result supports the emergency fund hypothesis. Such effects are captured only indirectly in the other studies using calendar year information. Cerchiara et al. (2009) show the importance of policy duration, calendar year, and product class. Milhaud et al. (2010) find the biggest surrender risks for policies that include a fiscality constraint (i.e., surrender charges apply only for a certain part of the contract duration). When the contract 
has reached the point at which the policyholder can surrender without penalty, the lapse risk increases significantly. Other relevant risk factors include policyholder age and method of payment (i.e., regular vs. single premiums). ${ }^{7}$

Overall, the empirical evidence underlines the importance of the interest rate as one of the most fundamental lapse drivers. This aspect is integrated in the dynamic lapse models presented in Section 2. Moreover, the empirical evidence makes clear that lapse rate models that are not driven by contract characteristics (such as policy duration and fiscal constraints) and other economic factors (such as unemployment rate) might significantly misjudge the true lapse risk. These factors are not very well incorporated in current lapse rate models so that significant need for future research can be taken from these empirical observations.

\section{Areas for Future Research}

Based on the above literature review, we now discuss potential areas for future research. We first analyze the design of lapse rate models, followed by a discussion of topics for future empirical research. Here we also discuss lapse risk mitigation techniques and factors that might influence policyholder behavior, such as the increasing availability of information.

\subsection{Design of Future Lapse Rate Models}

Lapse rate models usually take account of dynamic changes in interest rates and lapse. However, the growing importance of risk-based valuation and regulatory requirements for today’s insurance business will necessitate an extension of current models. We see three main fields of research that are crucial for the design of future lapse rate models in practice. Firstly, how are interaction, information, and individual or collective decision making reflected in dynamic lapsation? Secondly, how significant is the impact of adverse selection on dynamic lapses? And thirdly, how do policyholders behave in extreme scenarios?

\footnotetext{
7 Another recent paper which is not contained in Table 4 is the work by Pinquet et al. (2011) who use proportional hazard models to analyze long-term insurance contracts. This paper is not included in Table 4 since they analyze a product bundle with health, life, and long-term care components. They find that policyholders who lapse their contracts have better health histories than those that continue their contracts.
} 
The extant academic literature already provides some approaches to answering these three questions. With respect to the first question, Shumrak et al. (1999) discuss the interaction of policyholders and brokers and its impact on the decision to lapse. The impact of mass media advertising is treated by Anzilli and De Cesare (2007). With respect to the second question, Vannucci (2003) brings together adverse selection and the valuation of the surrender option. With respect to the third question, a framework for modeling policyholder behavior in extreme scenarios is presented by Loisel and Milhaud (2011). This field of research requires a deep analysis of historical data and policyholder needs as well as experimental results and other findings from behavioral finance. ${ }^{8}$ The Society of Actuaries' "Policyholder Behavior in the Tail” working group (PBITT) regularly performs surveys in order to assess dynamic lapsation and utilization models of US-based insurers for variable annuities and unit-linked products with secondary guarantees. Furthermore, modern techniques based on "extreme value theory” (see Xue, 2012) or “predictive modeling” (see Towers Watson, 2010) might help to explore policyholder behavior in the extreme tails.

A number of modeling issues are likely to emerge in the context of dynamic lapse rate models. For example, model and parameter uncertainty should be treated with particular caution. Incomplete data and an inflated level of aggregation can provide only weak empirical evidence. Highly aggregated lapse rate data and the lack of extreme scenario samples are especially challenging problems. These may become more acute in the near future due to Solvency II requirements regarding proper documentation and proof of accuracy of internal models. The latest "Variable Annuity Guaranteed Benefits Survey" (PBITT, 2012) revealed that many insurers rely on "best guess" or insufficient company experience for policyholder behavior under extreme conditions. In addition, integrating extensive dynamic lapse rate models with

8 For more information, we refer to Rothkopf (2003), Wilkinson (2008), Anderson and Stafford (2009), Hey and Lotito (2009), Luce (2010), Dhaene et al. (2011) and Viscusi et al. (2011). 
existing internal models might be difficult because of the architecture of these models or due to limited computational resources.

Regarding the literature on optimal dynamic lapsation assuming rational and risk-averse investors, it is eye-catching that all existing papers consider utility functions from the CRRA class. These utility functions are very popular especially for their mathematical tractability. They might, however, not necessarily describe the true decision making process. Other types of utility functions might therefore be considered in lapse research. One particular promising approach which has not yet been explored in lapse modeling might be the incorporation of reference based utility functions and other elements of prospect theory / behavioral insurance (see, e.g., Wakker et al., 1997).

Another aspect that needs consideration in actuarial modeling and pricing is that product type has an influence on lapse behavior. Thus, lapse risk mitigation techniques might need to be adapted to product type. Charging lapse fees, providing policyholders with appropriate and adequate information, and intelligent product design are among the main lapse risk mitigation techniques. For example, some insurers use lapse-supported pricing in order to be more competitive. Daily (2004) describes the risks associated with these methods. Other factors such as marketing campaigns and costs might also influence lapse behavior. In general, the effect of marketing measures on lapsation is mostly unexplored in actuarial literature. One of the few papers that analyses the effects of marketing on satisfaction, retention, and prices in the life insurance industry is Crosby and Stephens (1987). Both more theoretical and empirical research might be done to study the link between relationship marketing, customer satisfaction and lapsation in life insurance.

Finally, it might also be worthwhile to consider completely different fields of literature and to compare the cancellation of a life insurance contract with other economic events. In banking there is a variety of literature surrounding the sudden cancelation and withdrawal of deposits, 
especially following the work on bank runs by Diamond and Dibvig (1983). Also results on customer satisfaction and retention in other industries such as automobile or mobile phone industry might provide relevant insights for life insurance lapse. The cancellation of a mobile phone contract might not be directly comparable to lapse, but it might be interesting to study how other researchers model these types of events and what measures are used to mitigate such risks in these industries (see, e.g., Mittal and Kamakura, 2001).

\subsection{Avenues for Future Empirical Research}

The discussion in Section 2.2. shows many directions for future empirical research. First, it is noteworthy that there is no analysis of product and policyholder characteristics using U.S. data (see Panel B in Table 4). This is surprising, since, typically, there is a great deal of research that employs U.S. data, and very little outside of the U.S. market. However, when it comes to research on lapse, the opposite appears to be the case.

Moreover, we could find hardly any lapse research dealing with lines other than life insurance. For example, we could find hardly any research on lapse in health insurance or in other fields of long-term insurance; the only exception is the recent paper by Pinquet et al. (2011) discussed in Section 2.2. Also non-life insurance might be interesting to consider in this context. Although non-life contracts are typically set up for one year only, annual renewal is the norm, making lapse or retention a very important factor in this line of business. For life insurance, cancellation and embedded options have been broadly analyzed in recent years, but we do not know as much about the premium renewal process in non-life insurance. We found only one study, a German-language dissertation by Pohl (2009) empirically analyzing a portfolio of German motor insurance policies. From an economic point of view the lapse decision in life insurance is comparable to the renewal decision in the non-life sector so that a transfer of the ideas and methods can generate a fruitful area of future work.

Another interesting avenue for future research which is in the interconnection between the theoretical (modeling) and empirical work might be the development of a lapse prediction 
model. Such a model could be useful in designing programs geared toward the retention of customers shown to be likely to lapse (Prestele, 2006). The development of a prediction model requires additional model validation procedures, e.g., splitting the data set into a fitting and testing sample (see, e.g., Cerchiara et al., 2009; Kiesenbauer, 2011). Moreover, a number of alternative modeling approaches might be investigated, such as, e.g., fitting of polynomials or other appropriate functions to the different levels of the analyzed factors (see Eling and Kiesenbauer, 2011). This might allow a more profound analysis of interaction effects.

The life insurance business and its associated risks exhibit a long time horizon. Insurers thus need to identify emerging risks and their impact on today’s product design and risk management. Future lapse behavior will also be influenced by the regulator and legislation, market development, and policyholders' level of information. All these aspects might be integrated in empirical studies of lapse behavior, e.g., effects of new legislation on lapse rates. For example, the results by Milhaud et al. (2010) emphasize the importance of fiscal legislation to lapse rates.

Recent changes in legislation reveal potential political and regulatory trends. For example, in Germany, lapse fees have been capped and guaranteed surrender values have been raised (see Bundesministerium der Justiz, 2008); in Norway, lapse fees have been abolished (see Nordahl, 2008). The overall trend in Europe is to mandate higher surrender values, which may lead to more lapsation. Furthermore, regulatory changes such as Solvency II imply higher costs, encouraging policyholders to consider other forms of investment. Insurers also need to keep in mind that future insurance markets may be significantly different than today's: different products and growing consolidation of the insurance business will affect future lapse rates, too. Being alert to structural breaks and time effects is thus crucial, especially in light of long time horizons. 
Another recent development that might affect future lapse rates is the secondary market for life insurance. Gatzert et al. (2010) describe the impact of speculation against insurers by the emerging secondary market. Finally, policyholders are likely to become more and better informed due to an increasing number of independent agents and the availability of detailed product information and comparisons enabled by the Internet. In summary, it is safe to assume that in the future, policyholders' lapse behavior will be both more dynamic and more rational which might serve as an interesting basis for empirical work.

\section{Conclusion}

The intention of this paper was to review the extant academic literature on lapse in life insurance and to identify potential areas of new research in this important field. Lapse rate modeling has been a very active field of research in the last years, as evidenced by the 44 papers on lapse modeling considered in our review. Moreover, a fair amount of empirical work (another

12 papers reviewed here) has been done, especially on the issue of how environmental variables affect lapse. Research on individual policyholder and contract information is more scarce since such information is typically treated as confidential.

Although much has been done in recent years, there is still plenty of room for future research, both from a theoretical as well as from an empirical point of view. Challenges for lapse models are the inclusion of interaction effects, level of information, and individual or collective decision-making processes. Moreover, adverse selection and extreme scenarios should be incorporated in the models. On the empirical front, more can be done regarding other markets, prediction models, and the effects of new legislation or the increasing secondary market on lapse risk. The empirical methods applied in the life insurance sector could be applied to other branches of the insurance industry, e.g., to analyze drivers of renewal decisions in health and property-casualty sector. Our hope is thus that this paper will serve as an encouragement to additional theoretical and empirical research on lapse in years ahead. 


\section{References}

Albizzati, M.-O., Geman, H., 1994. Interest rate risk management and valuation of the surrender option in life insurance policies. Journal of Risk and Insurance 61(4), 616-637.

American Academy of Actuaries, 2005. Recommended approach for setting regulatory risk-based capital requirements for variable annuities and similar products, Report. American Academy of Actuaries, Boston, MA.

Anderson, L., Stafford, S., 2009. Individual decision-making experiments with risk and intertemporal choice. Journal of Risk and Uncertainty 38(1), 51-72.

Andreatta, G., Corradin, S., 2003. Fair value of life liabilities with embedded options: An application to a portfolio of Italian insurance policies. Working Paper. Astin Colloquium Berlin.

Anzilli, L., De Cesare, L., 2007. Valuation of the surrender option in unit-linked life insurance policies in a nonrational behavior framework. Working Paper. Quaderni DSEMS, Dipartimento di Scienze Economiche, Matematiche e Statistiche, Universita' di Foggia.

Bacinello, A. R., 2003a. Fair valuation of a guaranteed life insurance participating contract embedding a surrender option. Journal of Risk and Insurance 70(3), 461-487.

Bacinello, A. R., 2003b. Pricing guaranteed life insurance participating policies with annual premiums and surrender option. North American Actuarial Journal 7(3), 1-17.

Bacinello, A. R., 2005. Endogenous model of surrender conditions in equity-linked life insurance. Insurance: Mathematics and Economics 37(2), 270-296.

Bauer, D., Kiesel, R., Kling, A., Ruß, J., 2006. Risk neutral valuation of participating life insurance contracts. Insurance: Mathematics and Economics 39(2), 171-183.

Bernard, C., Lemieux, C., 2008. Fast simulation of equity-linked life insurance contracts with a surrender option. Proceedings of the 2008 Winter Simulation Conference, 444-452, IEEE Press.

Bundesministerium der Justiz 2008. Versicherungsvertragsgesetz.

CEA, 2009. Additional input to CEA comments on CEIOPS' CP49 on the mass lapse risk calibration. Position Paper. Brussels.

CEIOPS, 2009. CEIOPS Advice for level 2 implementing measures on Solvency II: Standard formula SCRArticle 109c life underwriting risk (former CP 49). Consultation Paper. Brussels.

CEIOPS, 2010. QIS5 Technical Specifications. Brussels.

Cerchiara, R. R., Edwards, M., Gambini, A., 2009. Generalized Linear Models in Life Insurance: Decrements and Risk factor analysis under Solvency II. Working Paper. AFIR Colloquium Rome.

Chen, Z., Vetzal, K., Forsyth, P., 2008. The effect of modeling parameters on the value of GMWB guarantees. Insurance: Mathematics and Economics 43(1), 165-173.

Cheung, K. C., Yang, H., 2005. Optimal stopping behavior of equity linked investment products with regime switching. Insurance: Mathematics and Economics 37(3), 599-614.

Consiglio, A., De Giovanni, D., 2010. Pricing the option to surrender in incomplete markets. Journal of Risk and Insurance 77(4), 935-957.

Cox, S. H., Lin, Y., 2006. Annuity lapse rate modeling: Tobit or not tobit? Working Paper. Society of Actuaries.

Crosby, L. A., Stephens, N., 1987. Effects of Relationship Marketing on Satisfaction, Retention, and Prices in the Life Insurance Industry. Journal of Marketing Research 24(4), 404-411

Daily, G. S., 2004. Lapse-supported pricing: Is it worth the risks? Working Paper.

Dar, A., Dodds, C., 1989. Interest rates, the emergency fund hypothesis and saving through endowment policies: Some empirical evidence for the U.K. Journal of Risk and Insurance 56(3), 415-433.

De Giovanni, D., 2010. Lapse rate modeling: A rational expectation approach. Scandinavian Actuarial Journal, 2010(1), 56-67.

Dhaene, J., Linders, D., Schoutens, W., Vyncke, D., 2011. The Herd Behavior Index: a new measure for systemic risk in financial markets. Research Report. FEB, K.U.Leuven.

Diamond, D. W., Dybvig, P. H. 1983. Bank Runs, Deposit Insurance, and Liquidity. Journal of Political Economy 91 (3), 401-419

EIOPA, 2011. EIOPA Report on the fifth Quantitative Impact Study (QIS5) for Solvency II. Brussels.

Eling, M., Kiesenbauer, D., 2011. What policy features determine life insurance lapse: An analysis of the German market. Journal of Risk and Insurance, forthcoming.

FSA, 2010, 2010 Survey of the Persistency of Life and Pensions Policies. London.

Gatzert, N., 2009. Implicit options in life insurance: An overview. Zeitschrift für die gesamte Versicherungswissenschaft 98(2), 141-164.

Gatzert, N., Huber, C., Schmeiser, H., 2010. Investment guarantees in unit-linked life insurance from the customer perspective. Zeitschrift für die gesamte Versicherungswissenschaft 99(5), 627-636.

Grosen, A., Jorgensen, P. L., 1997. Valuation of early exercisable interest rate guarantees. Journal of Risk and Insurance 64(3), 481-503. 
Grosen, A., Jorgensen, P. L., 2000. Fair valuation of life insurance liabilities: The impact of interest rate guarantees, surrender options, and bonus policies. Insurance: Mathematics and Economics 26(1), 37-57.

Harrington, S. E., 1992. Fair Policyholder runs, life insurance company failures, and insurance solvency regulation. Regulation 15(2), 27-37.

Hey, J., Lotito, G., 2009. Naive, resolute or sophisticated? A study of dynamic decision making. Journal of Risk and Uncertainty 38(1), 1-25.

Ho, T., Lee, S.B., Choi, Y., 2005. Practical considerations in managing variable annuities. Working paper,

Jensen, B., Jorgensen, P. L., Grosen, A., 2001. A finite difference approach to the valuation of path dependent life insurance liabilities. Geneva Papers on Risk and Insurance-Theory 26(1), 57-84.

Kagraoka, Y., 2005. Modeling insurance surrenders by the negative binomial model. Working Paper.

Kiesenbauer, D., 2011. Main determinants of lapse in the German life insurance industry. North American Actuarial Journal 16(1), 52-73.

Kim, C., 2005a. Modeling surrender and lapse rates with economic variables. North American Actuarial Journal 9(4), 56-70.

Kim, C., 2005b. Report to the Policyholder Behavior in the Tail Subgroups Project. Report. Society of Actuaries.

Kling, A., Ruß, J., Ruez, F., 2011. The impact of policyholder behavior on pricing, hedging, and hedge efficiency of withdrawal benefit guarantees in variable annuities. Working Paper. AFIR Colloquium Madrid.

Kochanski, M., 2010. Solvenzkapital für FLV unter Berücksichtigung von dynamischem Storno. Zeitschrift für die gesamte Versicherungswissenschaft 99(5), 689-710.

Kolkiewicz, A. W., Tan, K. S., 2006. Unit-linked life insurance contracts with lapse rates dependent on economic factors. Annals of Actuarial Science 1(1), 49-78.

Kraft, H., Steffensen, M., 2008. The policyholder's static and dynamic decision making of life insurance and pension payments. Blätter der DGVFM 29(2), 211-244.

Kuo, W., Tsai, C., Chen, W.-K., 2003. An empirical study on the lapse rate: The cointegration approach. Journal of Risk and Insurance 70(3), 489-508.

Le Courtois, O., Nakagawa, H., 2011. On surrender and default risks. Mathematical Finance, forthcoming.

Ledlie, M. C., Corry, D. P., Finkelstein, G. S., Ritchie, A. J., Su, K., Wilson, D. C. E., 2008. Variable annuities. British Actuarial Journal 14(2), 327-430.

Li, J., Szimayer, A., 2010. The effect of policyholders' rationality on unit-linked life insurance contracts with surrender guarantees. Working Paper.

LIMRA 2005. U.S. individual life persistency update. Report. LIMRA International.

Loisel, S., Milhaud, X., 2011. From deterministic to stochastic surrender risk models: Impact of correlation crises on economic capital. European Journal of Operational Research 214(2), 348-357.

Luce, R., 2010. Behavioral assumptions for a class of utility theories: A program of experiments. Journal of Risk and Uncertainty 41(1), 19-37.

Milevsky, M. A., Salisbury, T., 2001. The real option to lapse a variable annuity: Can surrender charges complete the market? Working Paper.

Milevsky, M. A., Salisbury, T. S., 2006. Financial valuation of guaranteed minimum withdrawal benefits. Insurance: Mathematics and Economics 38(1), 21-38.

Milhaud, X., Loisel, S., Maume-Deschamps, V., 2010. Surrender triggers in life insurance: Classification and risk predictions. Working Paper.

Mittal, V., Kamakura, W. A., 2001. Satisfaction, Repurchase Intent, and Repurchase Behavior: Investigating the Moderating Effect of Customer Characteristics. Journal of Marketing Research 38(1), 131-142.

Moenig, T., Bauer, D., 2011. Revisiting the Risk-Neutral Approach to Optimal Policyholder Behavior: A Study of Withdrawal Guarantees in Variable Annuities. Working Paper.

Moore, K. S., 2009. Optimal surrender strategies for equity-indexed annuity investors. Insurance: Mathematics and Economics 44(1), 1-18.

Moore, K. S., Young, V., 2005. Optimal design of a perpetual equity indexed annuity. North American Actuarial Journal 9(1), 57-72.

Morgan, E., 2010. The role and structure of profit participation products in the European life insurance market following Solvency II. Working Paper. LIFE Colloquium Munich.

Morgan, E., Kent, J., 2008. Dynamic policyholder behavior. Working Paper. Staple Inn Actuarial Society.

Nordahl, H. A., 2008. Valuation of life insurance surrender and exchange options. Insurance: Mathematics and Economics 42(3), 909-919.

Outreville, J. F., 1990. Whole-life insurance lapse rates and the emergency fund hypothesis. Insurance: Mathematics and Economics 9(4), 249-255.

Pinquet, J., M. Guillén, M. Ayuso, 2011, Commitment and Lapse Behavior in Long-Term Insurance: A Case Study, Journal of Risk and Insurance 78(4), 983-1002. 
PBITT 2012. Policyholder Behavior in the Tail: Variable Annuity Guaranteed Benefits - 2011 Survey Results. Report. Society of Actuaries.

Pohl, S., 2009. Hauptfälligkeitsstorno in der Kraftfahrtversicherung: Zeitdiskrete Hazardraten-Analyse mit linkstrunkierten Daten. Eul Verlag.

Prestele, A., 2006. Storno in der Lebensversicherung: Einflussfaktoren, Auswirkungen, Gegenmaßnahmen. VDM Verlag Dr. Müller.

Purushotham, M., 2005. U.S. Individual Life Persistency Update, Joint study sponsored by LIMRA International and the Society of Actuaries. Report. LIMRA International.

Renshaw, A. E., Haberman, S., 1986. Statistical analysis of life assurance lapses. Journal of the Institute of Actuaries 113, 459-497.

Rothkopf, B., 2003. Die Persönlichkeit als Erklärungsansatz interindividueller Unterschiede im Anlegerverhalten an der Börse. RWTH Aachen University.

Shen, W., Xu, H., 2005. The valuation of unit-linked policies with or without surrender options. Insurance: Mathematics and Economics 36(1), 79-92.

Shumrak, M., Greenbaum, M., Darley, V., Axtell, R., 1999. Modeling annuity policyholder behavior using behavioral economics and complexity science. Working Paper. Canadian Institute of Actuaries.

Smink, M., 1991. Risk measurement for asset liability matching, a simulation approach to single premium deferred annuities. Working Paper. AFIR Colloquium Brighton.

Steffensen, M., 2002. Intervention options in life insurance. Insurance: Mathematics and Economics 31(1), 7185.

Tanskanen, A. J., Lukkarinen, J., 2003. Fair valuation of path-dependent participating life insurance contracts. Insurance: Mathematics and Economics 33(3), 595-609.

Towers Watson 2010. Predictive Modeling for Life Insurers. Working Paper.

Tsai, C., Kuo, W., Chiang, D. M.-H., 2009. The distributions of policy reserves considering the policy-year structures of surrender rates and expense ratios. Journal of Risk and Insurance 76(4), 909-931.

Vannucci, E., 2003. The valuation of unit linked policies with minimal return guarantees under symmetric and asymmetric information hypotheses. Proceedings of the 6th Spanish-Italian Meeting on Financial Mathematics, Vol. II, 569-582.

Viscusi, W.K., Phillips, O., Kroll, S., 2011. Risky Investment Decisions: How Are Individuals Influenced by Their Groups? Vanderbilt Law and Economics Research Paper, No. 11-33.

Wakker, P., Thaler, R., Tversky, A., 1997. Probabilistic Insurance. Journal of Risk and Uncertainty 15(1), 7-28.

Watson Wyatt 2004. Calibration of the enhanced capital requirement for with-profit life insurers. Consultation Paper. FSA Library.

Wilkinson, N., 2008. An introduction to behavioral economics. Palgrave Macmillan.

Xue, Y., 2012. Exploring Policyholder Behavior in the Extreme Tail. Working Paper.

Zenios, S. A., 1999. Financial optimization. Cambridge University Press. 